\title{
Effectiveness of the power and speed dry-land training in female swimmers aged 15-16
}

\author{
AgATA GUZIK-KOPYTO ${ }^{1 *}$, KATARZYNA NOWAKOWSKA-LIPIEC ${ }^{1}$, ANNA NOCOŃ $^{2}$, \\ MAREK GZIK ${ }^{1}$, ROBERT MICHNIK ${ }^{1}$ \\ ${ }^{1}$ Department of Biomechatronics, Faculty of Biomedical Engineering, Silesian University of Technology, Zabrze, Poland. \\ 2 Students' Sports Club "Manta” Kochłowice, Ruda Śląska, Poland.
}

\begin{abstract}
Purpose: This work aimed to define the impact of the introduction of power and speed dry-land training in female swimmers aged 15-16 on the rise of time results at a distance of $200 \mathrm{~m}$ and on the increase of the strength level of the muscle groups in the elbow joint. Method: The investigations were conducted on a group of 28 junior female swimmers: group 1 (aged 13-14) with speed and endurance training based on "water" exercises; group 2 (aged 15-16) with extra power and speed dry-land training. The following parameters were analyzed: time results, the moments of muscle forces in the elbow joint at the extension and flexion movements in isokinetic conditions and the ratio of the values of moments of muscle forces of flexors in relation to extensors. Results: Statistically significant differences between groups were found for the following parameters: the time results from swimming $200 \mathrm{~m}$ with $(p<0.001)$ and without using lower limbs $(p=0.031)$, the ratio of the moments of muscle forces of flexors to extensors $(p<0.05)$. Conclusions: The results of the correlation analysis show that the higher the moments of muscle forces of flexors and extensors of the elbow joint, the shorter the time obtained in swimming $200 \mathrm{~m}$ in the freestyle stroke.
\end{abstract}

Key words: dry-land training, Biodex, muscle strength, muscle forces, junior female swimmers

\section{Introduction}

Swimming is one of the best-researched disciplines of sport in the scope of sport biomechanics [9]. Numerous studies in this discipline began as early as in 1905, when the resistance of water during swimming was measured with a dynamometer. Nowadays, this sport discipline is often analyzed in terms of biomechanics and physiology [9].

Investigations involve the impact of the forms of workout (water and dry-land training) on the time results obtained by competitors [24] as well as the influence of swimming training on the disproportions in muscular strength between upper limbs [29]. On the other hand, biomechanical tests of swimmers are often applied with a view to measuring and analyzing parameters, which in consequence may influence the selection of training techniques and effects, and what follows, the end result of a given swimmer [10]. Researchers have also been interested in prevention and treatment of injuries resulting from swimming [2], [3] as well as the dependence between muscle strength and time results obtained while swimming [30].

A parameter which is crucial to swimming is the driving or propelling force, which is most influenced by upper limbs. It was ascertained that well-trained swimmers achieve the highest values of this force during the movement of the upper limb over $78 \%$ of time of the whole cycle of movement [4]. The estimation of strength ability in athletes is most often conducted on the basis of the measurements of the moments of forces generated by particular groups of muscles in the joints of upper or lower limbs [15], [16], [19], [29].

One of the most popular swimming strokes is the freestyle stroke, in which a particular role is played by

\footnotetext{
* Corresponding author: Agata Guzik-Kopyto, Department of Biomechatronics, Faculty of Biomedical Engineering, Silesian University of Technology, ul. Roosevelta 40, 41-800 Zabrze, Poland. Phone: +48 32277 74 36, e-mail: agata.guzik-kopyto@polsl.pl

Received: December 15th, 2020

Accepted for publication: March 2nd, 2021
} 
flexor and extensor muscles of the elbow joint [3]. These muscles take part in the phases called: "the catch", "the pull" and "the push". In the catch and the pull phases, the key part is played by flexor muscles of the elbow joint - biceps brachii and brachialis. Considerable values of the propelling force generated by the action of the elbow joint flexors are obtained in "the pull" phase during the so-called "catch of the water". "The push" phase engages mainly extensor muscles of the elbow joint - triceps brachii [24]. Researchers have been looking for the dependence between strength parameters and the results obtained in the swimming pool [6], [24], [30]. Research works can be found which point out to a positive influence of dry-land power training on the results of sprint in swimming [7], [13], [25]. Several teams of researchers have signalled that dry-land power training improves the efficiency of swimming [7], [12], [13], [28]. Scientists and coaches agree that the training of young swimmers should include both dry-land workout and water training. In accordance with the latest guidelines for junior training, it is advisable to introduce strength training from the age of 15 , which is to ensure the increase in the muscle power and as a result enhance the outcome [14].

This research aimed to determine the impact of the introduction of power-speed training in swimmers aged $15-16$ on the increase of time results obtained at a distance of $200 \mathrm{~m}$ and the strength level of groups of muscles in the elbow joint. This work involved the investigations of the moments of muscle forces in the elbow joint in isokinetic conditions as well as time results at a distance $200 \mathrm{~m}$ in a group of junior female swimmers (aged 13-14) without the power and speed training and a group of junior female swimmers (aged 15-16) with the introduced power-speed training.

We hypothesize that the introduction of powerspeed training in swimmers aged 15-16 may improve the time results over a distance of $200 \mathrm{~m}$ and increases the level of moments of strength of the extensors and flexors in the elbow joint.

\section{Materials and methods}

\section{Participants}

The investigations were conducted on a group of 28 junior female swimmers specializing in the freestyle stroke. The tests were done one week after the end of the main swimming competition the swimmers had been preparing for. The test participants were divided according to the duration of their training period and workout load into two groups with an equal number of persons. The first group was made up by 14 female swimmers at the age of 13-14. The training of this group was based on water exercises. The second group consisted of 14 female swimmers aged 15-16. In the older group, the dry-land training was introduced in addition to the swimming-pool training. All tested swimmers declared their right-hand upper limb to be the dominant limb.

The characteristics of the studied groups of female swimmers are presented in Table 1. All study participants and their parents were informed about the purpose and method of the study and gave their written consent to participate in the study before the experiment began.

Table 1. Characteristics of the test group

\begin{tabular}{|l|c|c|c|}
\hline & Group 1 & Group 2 & $\begin{array}{c}\text { Group 1 } \\
\text { vs. Group 2 } \\
p \text {-value }\end{array}$ \\
\hline Number & 14 & 14 & n/a \\
\hline Age [years] & $13-14$ & $15-16$ & $<0.00001^{*}$ \\
\hline Body height [m] & $156 \pm 6$ & $166 \pm 6$ & $<0.00001^{*}$ \\
\hline Body weight [kg] & $44 \pm 6$ & $58 \pm 6$ & $0.00003^{*}$ \\
\hline BMI [kg/m $\left.{ }^{2}\right]$ & $18.1 \pm 2.2$ & $20.8 \pm 1.6$ & 0.227 \\
\hline $\begin{array}{l}\text { Average distance covered } \\
\text { in one workout }[\mathrm{km}]\end{array}$ & $3.77 \pm 0.24$ & $4.47 \pm 0.3$ & $<0.00001^{*}$ \\
\hline $\begin{array}{l}\text { Number of trainings } \\
\text { in the season }\end{array}$ & $197 \pm 4$ & $272 \pm 5$ & $<0.00001^{*}$ \\
\hline
\end{tabular}

* Statistically significant differences.

\section{Training methods}

The swimmers in the younger group (Group 1) took part in an average of 6 workouts per week, each lasting 90 minutes. They swam an average of $3.77 \mathrm{kms}$ per workout. A typical training unit consisted of about $1 \mathrm{~km}$ of training in the EN1 energy zone, about $2 \mathrm{~km}$ in different energy zones (depending on the stage of preparation), and about $1 \mathrm{~km}$ of swimming in the REC zone.

A typical training unit in the older group (Group 2) in water consists of about $1 \mathrm{~km}$ of training in the REC and EN1 energy zones, about $3 \mathrm{~km}$ in different energy zones (depending on the stage of preparation), and about $1 \mathrm{~km}$ of swimming in the REC zone. In addition to training in the pool, the older group was also introduced to training on dry land. The female athletes in this group performed on average 9 workouts a week in water. Land training included stabilization exercises twice a week, resistance band training in water and on land once a week, and gym exercises once 
a week. The total training time on land during the week was 180 minutes. The stabilization training lasted for 30 minutes and consisted of performing a series of exercises lasting between 30 to 60 seconds on the deep muscles called ,the core". Resistance band training in the water consisted of stretching the band in the water after jumping from a post and swimming at maximum speed. Four series of 25 meters each were performed most frequently. The resistance band training on land consisted of flexion and extension movements at the elbow joint and flexion and extension movements at the shoulder joint with the use of the resistance bands. Three to five exercises of three sets of 20 repetitions each were performed, with varying lengths of breaks. Training at the gym consisted of a cardio warm-up lasting 10-15 minutes, followed by about five strength exercises for the upper limb muscles, three sets of 10 repetitions each on isometric machines, and two exercises with dumbells for the flexor and extensor muscles of the elbow joint (3 sets of 10 repetitions). Gradually, the weight of the workout equipment used was increased over the course of the season. Two weeks before the main competition, in the so-called "tapering" phase, the swimmers no longer performed strength training on land, because during this period the loads are reduced to adequately prepare the body for the competition [23].

\section{Measurements}

The measurements of the moments of muscle forces in the elbow joint in extension and flexion were conducted in isokinetic conditions at angular velocity of 60,180 and $300 \%$ s. The investigations were carried out at a testing station Biodex System 4 Pro (Biodex system 3, Biodex Medical Systems, Inc., NY, USA). The measurement of each participant began with the adjustment of the chair in order to create comfortable conditions for the execution of exercises for each female swimmer. During each measurement, participants alternately made five movements of extension and flexion with each upper limb at each velocity. Between the repetitions, swimmers had a 30 -second interval for resting. The results of the moments of muscle forces of extensors and flexors were compared to the body mass.

The time was measured for the participants swimming at a distance of $200 \mathrm{~m}$ in the freestyle stroke $\left(t_{1}\right)$ and in the freestyle stroke with a pull buoy between thighs $\left(t_{2}\right)$ in order to eliminate the action of legs. The measurements were conducted in a 25 -metre swimming pool. The start was done from the water, the turns were open turns without underwater glide.

\section{Statistical analysis}

Within the framework of this work, a statistical analysis of the obtained measurement results was performed. Quantitative variables of the parameters analyzed in this study were described using a mean value, standard deviation (std), median, maximum and minimum values. The conducted statistical analyses adopted the level of significance $p<0.05$. The normality of distribution of the analyzed parameters was verified using the Shapiro-Wilk test ( $p$-value $\geq 0.05$ indicates normal distribution). In order to compare the differences in the analyzed quantitative variables between two groups of female swimmers, the Student's $t$-test and the Mann-Whitney $U$-test were used for the parameters of normal distribution and for the variables without normal distribution, respectively. Statistically significant differences between the results obtained for the right and left upper limbs were checked using the Student's $t$-test for dependent samples or the Wilcoxon test. In order to check the dependence between the time of swimming $200 \mathrm{~m}$ in the freestyle stroke and $200 \mathrm{~m}$ in the freestyle stroke without using the lower limbs and the values of the moments of muscle forces in the elbow joint, the Pearson correlation coefficient was determined. The software programme Statistica 13.1 by the Statsoft company was used for statistical calculations.

\section{Results}

In Table 2, the descriptive statistics of the time results obtained from swimming $200 \mathrm{~m}$ in the freestyle stroke and $200 \mathrm{~m}$ in the freestyle stroke without using lower limbs, the maximum values of the moments of muscle forces in the elbow joint in relation to the body mass during the movements of flexion and extension for various angular velocities and the ratio of maximum moments of flexors' forces to extensors' forces in the elbow joint are presented.

The mean value of the elbow joint extensor torque was higher in the group of older swimmers for the $60 \%$ test (by about $9 \mathrm{~N} \cdot \mathrm{m} \cdot \mathrm{kg}^{-1}$ ), while for the $180^{\circ} / \mathrm{s}$ and $300 \%$ s a higher mean value (by about $15 \mathrm{~N} \cdot \mathrm{m} \cdot \mathrm{kg}^{-1}$ ) was recorded in the group of younger swimmers. In group 2, higher mean values of elbow joint flexor torque were recorded for almost every test. The greatest differences in mean values were noted for the $60^{\circ} / \mathrm{s}$ test $\left(3.8 \mathrm{~N} \cdot \mathrm{m} \cdot \mathrm{kg}^{-1}\right.$ for the right upper limb and $7.96 \mathrm{~N} \cdot \mathrm{m} \cdot \mathrm{kg}^{-1}$ for the left upper limb). For the $180^{\circ} / \mathrm{s}$ test, the mean values of the elbow flexor torque for the right upper limb were similar in both groups of 
Table 2. Distribution of results obtained in groups 1 and 2

\begin{tabular}{|c|c|c|c|c|}
\hline & Group 1 & Group 2 \\
\hline & & & $\begin{array}{c}\text { Mean } \pm \mathrm{SD}(\min -\max ) \\
p \text {-value from Shapiro-Wilk test }\end{array}$ & $\begin{array}{c}\text { Mean } \pm \mathrm{SD}(\min -\max ) \\
p \text {-value from Shapiro-Wilk test }\end{array}$ \\
\hline \multicolumn{3}{|c|}{$t_{1}[\mathrm{~s}]$} & $154.6 \pm 9.5(141.5-171.2) 0.647$ & $138.5 \pm 5.2(128.3-147.2) 0.984$ \\
\hline \multicolumn{3}{|c|}{$t_{2}[\mathrm{~s}]$} & $172.8 \pm 13.1(155.3-195.2) 0.645$ & $162.0 \pm 10.3(151.5-188.2) \mathbf{0 . 0 0 8}$ \\
\hline \multirow{6}{*}{$60^{\circ} / \mathrm{s}$} & \multirow{2}{*}{\begin{tabular}{|l|} 
Extensors \\
{$\left[\mathrm{N} \cdot \mathrm{m} \cdot \mathrm{kg}^{-1}\right]$} \\
\end{tabular}} & $\mathrm{R}$ & $80.43 \pm 12.94(57.50-98.70) \mathbf{0 . 7 4 1}$ & $73.77 \pm 18.64(35.60-102.90) \mathbf{0 . 7 4 4}$ \\
\hline & & $\mathrm{L}$ & $82.19 \pm 18.20(55.60-116.10) \mathbf{0 . 3 6 9}$ & $70.59 \pm 22.48(22.90-93.70) 0.032$ \\
\hline & \multirow{2}{*}{$\begin{array}{l}\text { Flexors } \\
{\left[\mathrm{N} \cdot \mathrm{m}^{\mathrm{kg}} \mathrm{kg}^{-1}\right]} \\
\end{array}$} & $\mathrm{R}$ & $34.62 \pm 8.02(22.80-47.50) \mathbf{0 . 3 1 9}$ & $38.42 \pm 9.09(26.10-52.40) \mathbf{0 . 3 7 4}$ \\
\hline & & $\mathrm{L}$ & $33.21 \pm 7.70(22.90-51.10) \mathbf{0 . 4 4 6}$ & $41.17 \pm 9.55(31.20-58.10) 0.019$ \\
\hline & \multirow{2}{*}{$\begin{array}{l}\text { Flexors/ } \\
\text { extensors }\end{array}$} & $\mathrm{R}$ & $0.43 \pm 0.08(0.32-0.58) \mathbf{0 . 8 0 9}$ & $0.54 \pm 0.14(0.35-0.88) \mathbf{0 . 1 8 5}$ \\
\hline & & $\mathrm{L}$ & $0.41 \pm 0.08(0.26-0.53) \mathbf{0 . 4 6 3}$ & $0.65 \pm 0.28(0.39-1.45) 0.006$ \\
\hline \multirow{6}{*}{$180^{\circ} / \mathrm{s}$} & \multirow{2}{*}{$\begin{array}{l}\text { Extensors } \\
{\left[\mathrm{N} \cdot \mathrm{m}^{\mathrm{kg}}{ }^{-1}\right]} \\
\end{array}$} & $\mathrm{R}$ & $74.61 \pm 16.10(48.60-104.60) \mathbf{0 . 7 5 5}$ & $59.41 \pm 28.96(15.40-100.30) \mathbf{0 . 2 5 5}$ \\
\hline & & $\mathrm{L}$ & $76.69 \pm 18.43(54.00-123.30) \mathbf{0 . 1 3 1}$ & $61.03 \pm 25.66(20.96-94.80) 0.030$ \\
\hline & \multirow{2}{*}{\begin{tabular}{|l|} 
Flexors \\
{$\left[\mathrm{N} \cdot \mathrm{m}^{\prime} \mathrm{kg}^{-1}\right]$}
\end{tabular}} & $\mathrm{R}$ & $35.16 \pm 8.59(21.20-52.90) \mathbf{0 . 9 8 1}$ & $34.78 \pm 12.60(15.80-56.90) \mathbf{0 . 7 7 7}$ \\
\hline & & $\mathrm{L}$ & $33.99 \pm 7.31(24.80-47.00) 0.034$ & $37.88 \pm 13.01(17.40-57.60) \mathbf{0 . 6 5 3}$ \\
\hline & \multirow{2}{*}{$\begin{array}{l}\text { Flexors/ } \\
\text { extensors }\end{array}$} & $\mathrm{R}$ & $0.49 \pm 0.16(0.28-0.95) 0.005$ & $0.70 \pm 0.31(0.33-1.27) \mathbf{0 . 1 1 9}$ \\
\hline & & $\mathrm{L}$ & $0.46 \pm 0.14(0.30-0.85) 0.019$ & $0.73 \pm 0.46(0.38-2.21)<0.0001$ \\
\hline \multirow{6}{*}{$300^{\circ} / \mathrm{s}$} & \multirow{2}{*}{$\begin{array}{l}\text { Extensors } \\
{\left[\mathrm{N} \cdot \mathrm{m} \cdot \mathrm{kg}^{-1}\right]}\end{array}$} & $\mathrm{R}$ & $76.61 \pm 16.56(51.80-103.10) \mathbf{0 . 4 9 3}$ & $62.62 \pm 29.46(18.80-117.20) \mathbf{0 . 2 4 3}$ \\
\hline & & $\mathrm{L}$ & $76.66 \pm 14.04(52.80-101.60) \mathbf{0 . 9 6 4}$ & $60.95 \pm 27.51(21.35-94.40) 0.012$ \\
\hline & \multirow{2}{*}{\begin{tabular}{|l|} 
Flexors \\
{$\left[\mathrm{N} \cdot \mathrm{m}^{-\mathrm{kg}^{-1}}\right]$}
\end{tabular}} & $\mathrm{R}$ & $34.76 \pm 8.27(21.10-51.80) \mathbf{0 . 6 4 1}$ & $36.57 \pm 13.28(13.90-62.30) \mathbf{0 . 7 5 3}$ \\
\hline & & $\mathrm{L}$ & $35.88 \pm 9.07(25.70-54.70) 0.104$ & $36.38 \pm 11.60(20.70-56.80) \mathbf{0 . 3 8 0}$ \\
\hline & \multirow{2}{*}{\begin{tabular}{|l|} 
Flexors/ \\
extensors
\end{tabular}} & $\mathrm{R}$ & $0.47 \pm 0.13(0.30-0.81) \mathbf{0 . 1 3 6}$ & $0.68 \pm 0.31(0.33-1.40) \mathbf{0 . 1 9 6}$ \\
\hline & & $\mathrm{L}$ & $0.48 \pm 0.13(0.32-0.69) \mathbf{0 . 1 6 2}$ & $0.69 \pm 0.26(0.39-1.25) \mathbf{0 . 2 7 7}$ \\
\hline
\end{tabular}

$\mathrm{R}$ - right upper limb, $\mathrm{L}$ - left upper limb, the p-value for normal distribution has been bolded.

Table 3. Results of the analysis of statistically significant differences in the examined parameters between groups 1 and 2 of female swimmers between the right and left upper limb

\begin{tabular}{|c|c|c|c|c|c|}
\hline & & & $\begin{array}{l}\text { Differences in the examined } \\
\text { parameters between groups } 1 \\
\text { and } 2 ; p \text {-value (Student's } t \\
\text { or Mann-Whitney } U \text {-test) }\end{array}$ & $\begin{array}{c}\text { Differences in the examined } \\
\text { parameters between the right } \\
\text { and left upper limb in group 1; } \\
p \text {-value (Student's } t \\
\text { or Wilcoxon test) }\end{array}$ & $\begin{array}{c}\text { Differences in the examined } \\
\text { parameters between the right } \\
\text { and left upper limb in group 2; } \\
p \text {-value (Student's } t \\
\text { or Wilcoxon test) }\end{array}$ \\
\hline \multicolumn{3}{|c|}{$\mathrm{t}_{1}[\mathrm{~s}]$} & $<0.001$ & $\mathrm{n} / \mathrm{a}$ & $\mathrm{n} / \mathrm{a}$ \\
\hline \multicolumn{3}{|c|}{$\mathrm{t}_{2}[\mathrm{~s}]$} & 0.031 & $\mathrm{n} / \mathrm{a}$ & $\mathrm{n} / \mathrm{a}$ \\
\hline \multirow{6}{*}{$60^{\circ} / \mathrm{s}$} & \multirow{2}{*}{ Extensors } & $\mathrm{R}$ & 0.282 & \multirow{2}{*}{0.492} & \multirow{2}{*}{0.594} \\
\hline & & $\mathrm{L}$ & 0.395 & & \\
\hline & \multirow{2}{*}{ Flexors } & $\mathrm{R}$ & 0.252 & \multirow{2}{*}{0.443} & \multirow{2}{*}{0.178} \\
\hline & & $\mathrm{L}$ & 0.014* & & \\
\hline & \multirow{2}{*}{$\begin{array}{l}\text { Flexors / } \\
\text { Extensors }\end{array}$} & $\mathrm{R}$ & $0.018^{*}$ & \multirow{2}{*}{0.373} & \multirow{2}{*}{$0.031 *$} \\
\hline & & $\mathrm{L}$ & $0.002 *$ & & \\
\hline \multirow{6}{*}{$180^{\circ} / \mathrm{s}$} & \multirow{2}{*}{ Extensors } & $\mathrm{R}$ & 0.098 & \multirow{2}{*}{0.41} & \multirow{2}{*}{0.706} \\
\hline & & $\mathrm{L}$ & 0.301 & & \\
\hline & \multirow{2}{*}{ Flexors } & $\mathrm{R}$ & 0.926 & \multirow{2}{*}{0.73} & \multirow{2}{*}{0.33} \\
\hline & & $\mathrm{L}$ & 0.395 & & \\
\hline & \multirow{2}{*}{$\begin{array}{l}\text { Flexors / } \\
\text { Extensors }\end{array}$} & $\mathrm{R}$ & 0.051 & \multirow{2}{*}{0.397} & \multirow{2}{*}{0.975} \\
\hline & & $\mathrm{L}$ & $0.007^{*}$ & & \\
\hline \multirow{6}{*}{$300 \% \mathrm{~s}$} & \multirow{2}{*}{ Extensors } & $\mathrm{R}$ & 0.133 & \multirow{2}{*}{0.986} & \multirow{2}{*}{0.638} \\
\hline & & $\mathrm{L}$ & 0.241 & & \\
\hline & \multirow{2}{*}{ Flexors } & $\mathrm{R}$ & 0.669 & \multirow{2}{*}{0.695} & \multirow{2}{*}{0.951} \\
\hline & & $\mathrm{L}$ & 0.900 & & \\
\hline & \multirow{2}{*}{$\begin{array}{l}\text { Flexors / } \\
\text { Extensors }\end{array}$} & $\mathrm{R}$ & $0.026^{*}$ & \multirow{2}{*}{0.794} & \multirow{2}{*}{0.875} \\
\hline & & $\mathrm{L}$ & $0.011^{*}$ & & \\
\hline
\end{tabular}

$\mathrm{R}$ - right upper limb, L - left upper limb, * statistically significant differences. 
swimmers, while for the left limb the difference was less than $4 \mathrm{~N} \cdot \mathrm{m} \cdot \mathrm{kg}^{-1}$. For the $300^{\circ} / \mathrm{s}$ test, the differences between the mean values in both groups did not exceed $2 \mathrm{~N} \cdot \mathrm{m} \cdot \mathrm{kg}^{-1}$. In group 2, a higher ratio of maximum moments of flexors' forces to extensors' forces in the elbow joint was recorded for all tests.

In Table 3, the results of the Student's $t$-test and the Mann-Whitney $U$-test revealing the differences in the analyzed quantitative variables between two groups of female swimmers are shown.

Statistically significant differences were observed between group 1 and group 2 of the swimmers for the swimming time at a distance of $200 \mathrm{~m}$ in the freestyle stroke $(p<0.001)$ and $200 \mathrm{~m}$ in the freestyle stroke without using lower limbs $(p=0.031)$.

Statistically significant differences in the values of moments of muscle forces between group 1 and group 2 were noticed only for left flexors $(p=0.014)$ at an angular velocity of $60^{\circ} \mathrm{s}$. For other angular velocities, no differences were observed between the groups in respect of maximum values of the moments of the forces of extensors and flexors of the elbow joint, however, statistically significant differences were noted between groups 1 and 2 in the value of the ratio of maximum moments of the flexors' forces to the extensors' forces in the elbow joint for almost all conditions of the measurements (Table 3). Neither group showed any statistically significant differences in the maximum values of the moments of muscle forces in the elbow joint between the right and left upper limb.

The results of the Pearson correlation coefficient between the time of swimming $200 \mathrm{~m}$ in the freestyle stroke and $200 \mathrm{~m}$ in the freestyle stroke without using the lower limbs and the values of the moments of muscle forces in the elbow joint in groups 1 and 2 are presented in Table 4.

A statistically strong or moderately significant linear dependence was found between the time results obtained from swimming $200 \mathrm{~m}$ in the freestyle stroke and the time from swimming $200 \mathrm{~m}$ in the freestyle stroke without using lower limbs and almost all values of the moments of muscle forces in the elbow joint in group 2 of the female swimmers. In Figure 1, the dependence (scatter diagram) between the time obtained from swimming $200 \mathrm{~m}$ in the freestyle stroke and the values of the moments of muscle forces in the elbow

Table 4. Pearson's linear correlation coefficients between the time obtained from swimming $200 \mathrm{~m}$ in the freestyle stroke and $200 \mathrm{~m}$. in the freestyle stroke without using lower limbs and the values of the moments of muscle forces in the elbow joint

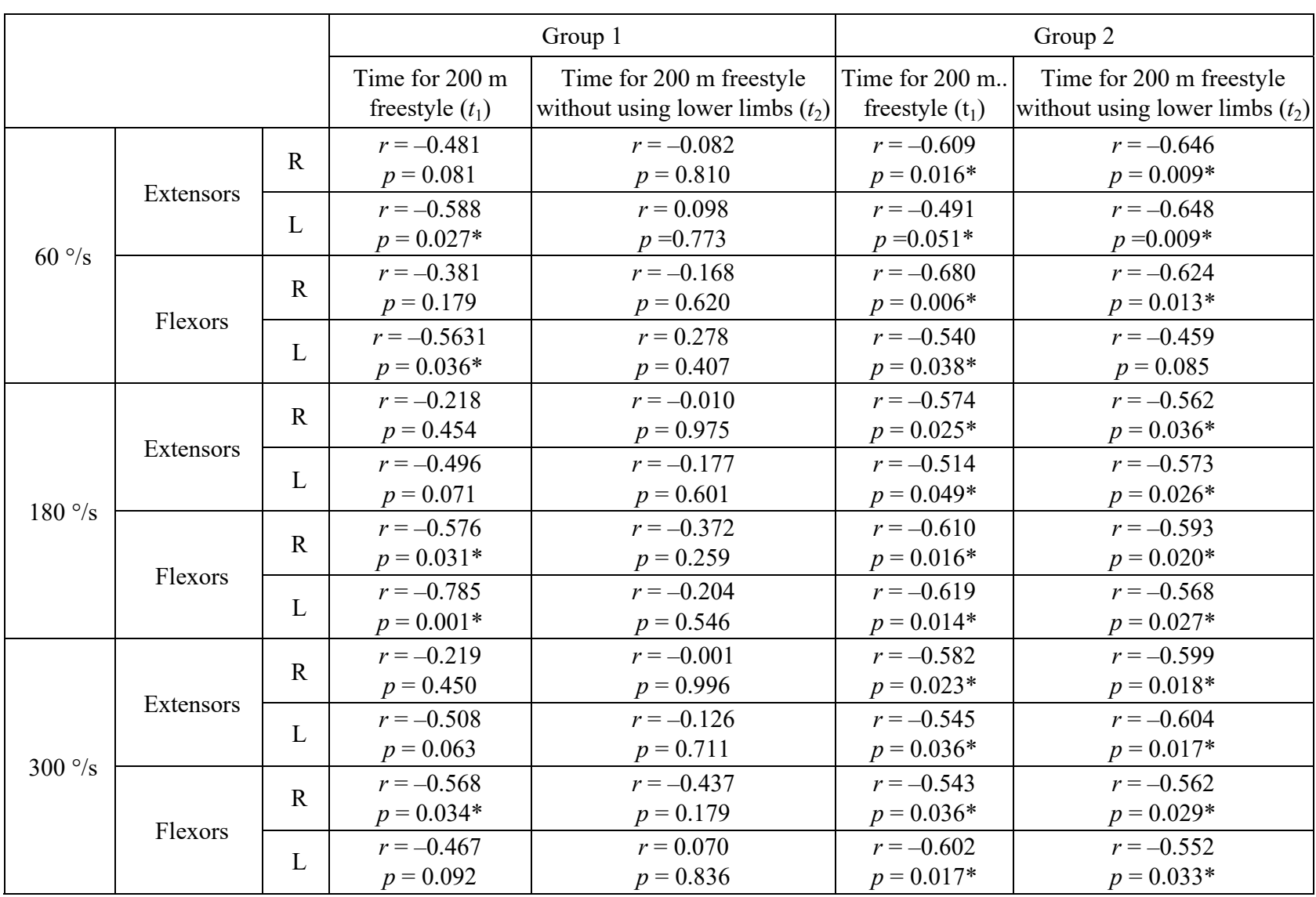

$\mathrm{R}$ - right upper limb, L - left upper limb, * the correlation value is statistically significant. 
joint in isokinetic conditions at an angular velocity of $60 \%$ is shown.

In group 1, no statistically significant correlations were observed between time $t_{2}$ and the values of the moments of muscle forces. As far as time $t_{1}$ is concerned, moderate correlations were noted solely for a part of the analyzed values of the moments of muscle forces in the elbow joint.

\section{Discussion}

This work aimed to determine the impact of power and speed training on female swimmers aged 15-16, which was introduced in order to increase their time results at a distance of $200 \mathrm{~m}$ and the level of strength of the groups of muscles of the elbow joint. The evaluation of the influence of the implemented power and speed training was carried out comparing the following results: time results obtained at a distance of $200 \mathrm{~m}$ in the freestyle stroke, measurements of muscle forces moments in the elbow joint in extension and flexion in isokinetic conditions at angular velocities $60 \% \mathrm{~s}, 180 \%$ s and $300 \%$ s and the ratio of the values of the moments of muscle forces of flexors to extensors for two groups of female swimmers. Group 1 consisted of swimmers who were assigned according to power and speed training based on exercises done in the water, whereas group 2 included swimmers who, in addition to swimming-pool training, had to do power and speed dry-land training. The additional training involved stabilization exercises, training with resistance bands in the water and on land as well as workout in the gym.

The conducted statistical analysis revealed statistically significant differences between the time results obtained at a distance of $200 \mathrm{~m}$ in the freestyle stroke by female swimmers from both groups. The majority of swimmers in group 1 took a longer time to cover this distance than swimmers from group 2. It was ascertained that the introduction of additional power and speed dry-land training considerably improved the results obtained from swimming in the freestyle stroke. It was observed that the higher the values of the moments of muscle forces of elbow joint flexors and extensors, the shorter the time obtained in swimming at a distance of $200 \mathrm{~m}$ in the freestyle stroke. This fact was confirmed by the results of the analysis of the correlation between time and the values of the forces moments (Table 4). This dependence can be clearly seen for the results obtained for swimmer group 2, which is presented in the scatter diagram in Fig. 1. In the younger group, the correlation between

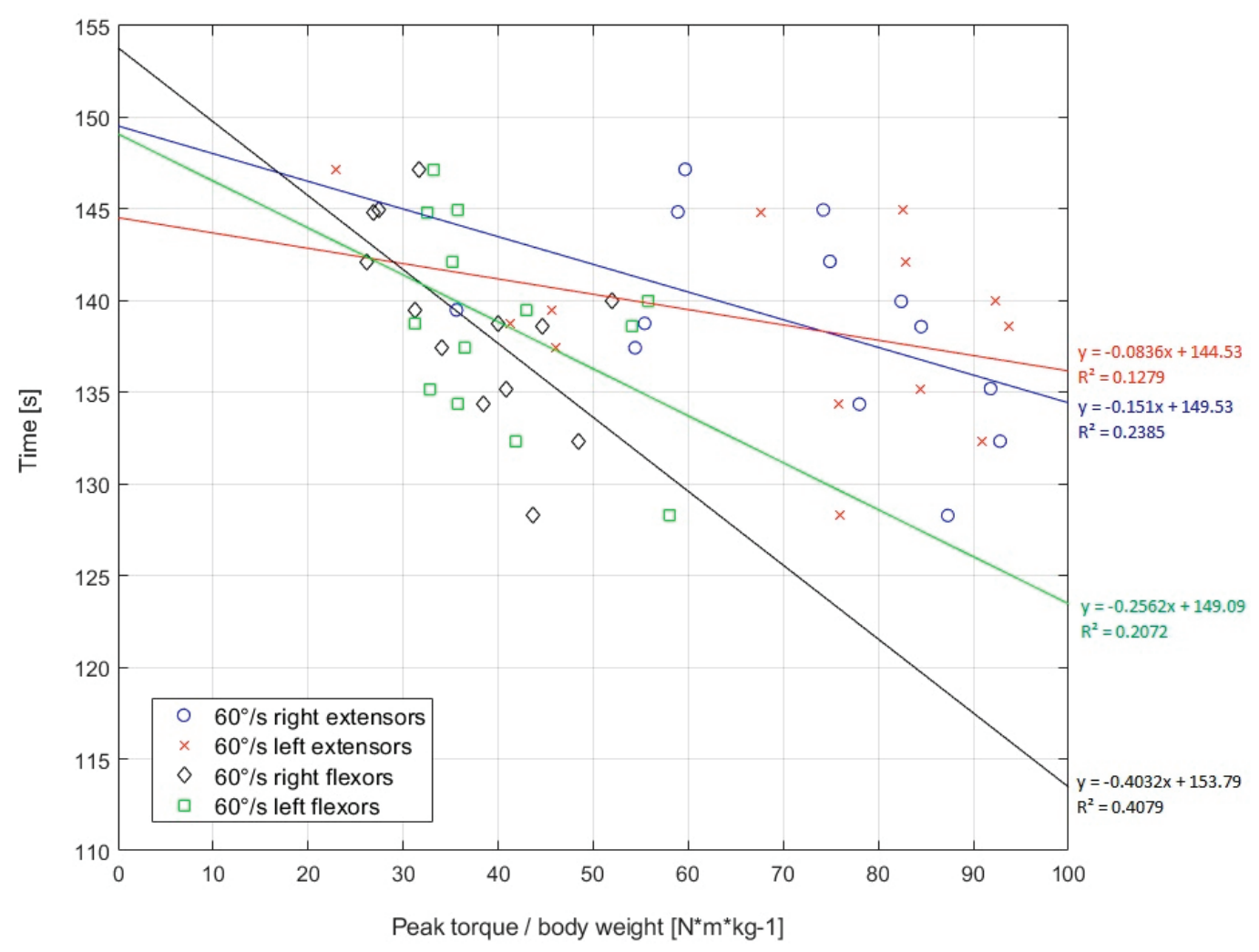

Fig. 1. Dependence between time obtained from swimming $200 \mathrm{~m}$ in the freestyle stroke and the values of moments of muscle forces in the elbow joint in isokinetic conditions at an angular velocity of $60^{\circ} / \mathrm{s}$ 
time and muscle forces moments with reference to the body mass occurs only for the time of swimming $200 \mathrm{~m}$ in the freestyle stroke in several cases (Table 4). The discrepancy in the results from the correlation analysis between time and the values of the moments of body forces between the younger group and the older group of female swimmers can be explained by the theory of "competitor's long-term development" [14], which is often applied by qualified coaches. This theory claims that developmental stages of a competitor should be linked to certain sports results. Therefore the competitor should be subjected to various stimuli in particular phases of their development. For that reason, the rule of "training for the sake of training" is applied to sports contestants aged 13-14. This includes numerous training methods focusing on the improvement of technique and stamina of the swimmer. The subsequent stage introduces power workout in the age group 15-16. Coaches readily introduce exercises of swimming using only upper limbs by immobilizing lower limbs with a pull buoy. The above-mentioned workout aims to force the competitor to swim with even better technique of the upper limbs than normal. This fact may account for the lack of correlation between the time of swimming $200 \mathrm{~m}$ in the freestyle stroke with a pull buoy between thighs and the values of the moments of muscle forces for the group of younger swimmers - during swimming using only upper limbs the technique of movements was of even greater importance.

On the basis of the obtained results it can be deduced that the inclusion of the power and speed dryland training may have a positive effect on the improvement of time results in swimming at a distance of $200 \mathrm{~m}$ in the freestyle stroke. Some works which are concerned with the impact of applied training methods on the swimmers' results can be found in the research literature [7], [13], [24], [25], [27]. Costill [7] as well as Stewart and Hopkins [26] wrote in their works that the improvement of swimming results depends on the specificity of training methods. Costill [7] proved a positive influence of power dry-land training of upper limbs on the efficiency in sprint swimming. In their research, Smith et al. [25] showed a strong relationship between the endurance of the upper part of the body and the results in sprint swimming at a distance of $25 \mathrm{~m}$ and $50 \mathrm{~m}$. The impact of various training stimuli on the time and values of the moments of muscle forces was studied by Girold et al. [13]. These authors combined methods of water training with resistance training on dry-land and training in the water with resistance swimming. After 12 weeks of diverse training, the swimmers showed a consider- able increase in the moments of forces in the elbow joint, measured in isometric and concentric conditions, as well as the shortening of the time needed to cover a distance of $50 \mathrm{~m}$ in the freestyle stroke. The above-mentioned studies confirm a positive influence of both dry-land and water resistance training" on the values of force parameters and the times obtained by female swimmers in sprint swimming [13]. However, based on the results obtained for a group of young male swimmers by Sadowski et al. [24], it cannot be explicitly stated that power dry-land training performed on an ergometer improved the swimming results. There is also research which challenges a positive effect of the resistance training [27]. In their work, Tanaka and Swensen [27] suggest that traditional dry-land resistance training does not improve swimming results, whereas water resistance training increases the speed of swimming. The majority of analyzed literature titles, similarly to the present work, showed a positive influence exerted by resistance training in swimmers.

When selecting a method of training, a factor which should be taken into consideration is the distance which swimmers specialize in. The distance length may also influence the values of force parameters. According to Lawsirirat et al. [21], competitors specializing in short distances achieve higher values of force moments in the upper limb joints than middle-distance and longdistance competitors.

The statistical analyses conducted within the framework of this work also showed that, almost in every case, there were no statistically significant differences between the values of the moments of muscle forces of extensors and flexors of the elbow joint between groups 1 and 2 . Statistically significant differences were observed only for left flexors $(p=0.014)$ at an angular velocity of $60 \%$ s (Table 3 ). The values of the moments of muscle forces for left flexors at an angular velocity of $60^{\circ} \mathrm{s}$ were considerably higher in group 2 . In relation to the mean values obtained by younger female swimmers, the difference equalled $7.96\left[\mathrm{~N} \cdot \mathrm{m} \cdot \mathrm{kg}^{-1}\right]$. On the basis of the values of the moments of muscle forces in the elbow joint obtained for groups 1 and 2, it cannot be deduced that the introduced power and speed training has an effect on the increase of the muscle force level of extensors and flexors of the elbow joint.

However, the scope of this analysis also involved the ratio of the moments of muscle forces of flexors to extensors in the elbow joint. It was shown that this ratio was significantly different between groups of female swimmers almost in all conditions of the measurements of the moments of muscle forces in the elbow joint (Table 3). In group 2, the above-mentioned ratio was 
higher by $25 \%$ in the right-hand elbow joint and by $59 \%$ in the left-hand elbow joint for the test conducted at an angular velocity of $60 \%$. Moreover, mean values of this dependence obtained for group 2 were higher by over $40 \%$ in relation to the results of group 1 in the case of tests carried out at other angular velocities. The above-mentioned results may suggest that the power and speed training introduced in group 2 may be of importance in balancing the disproportion of muscle forces of extensors and flexors of the elbow joint. The ratio obtained in the group of older female swimmers (group 2) at an angular velocity of $60 \%$ falls within the boundaries of the standard isokinetic data for women at the age of 15-30 years [17].

It should also be emphasized that no statistically significant differences were observed between the values of the moments of muscle forces in the elbow joint between the right and left upper limbs in both groups of female swimmers. The investigations carried out by Wiążewicz et al. [29] did not reveal differences between the values of the moments of muscle forces in the shoulder joint between the right and left upper limb. The above-mentioned results may signify that a correct swimming technique enables loading of the right and left side of the body in an even way.

The subject literature includes some scientific articles which are concerned with the determination of the moments of muscle forces in isometric and isokinetic conditions in the upper limb joints in male swimmers [1]-[3], [6], [13], [21], [22], [29]. Although many authors focus on the values of moments in the humeral joint [2], [3], [6], [29] there were also investigations connected with the determination of the moments of muscle forces in the elbow joint in male swimmers [1], [13], [21], [22]. Mean values of the moments of extensors' forces in the elbow joint, measured in isokinetic conditions at velocities of $180 \% \mathrm{~s}$ and $300 \%$ s obtained for the female swimmers from group 1 tested within this research, were significantly higher in comparison with the results of female swimmers in the same age group tested by Lewis et al. [22]. What was comparable was the mean values of the moments of flexors' forces of the elbow joint measured in isokinetic conditions at velocities of $180^{\circ} / \mathrm{s}$ and $300^{\circ} / \mathrm{s}[22]$.

Our results show that in the older swimmers the results are better, which indicates that the introduction of dry-land training improves the results. Dry-land training included stabilization exercises twice a week, resistance band training in water and on land once a week, and gym exercises once a week. This better results obtained for the group of older swimmers may also be caused by changes in anthropometric and mo- tor characteristics resulting from the natural process of adolescence and growing up.

Authors of this research are fully aware of the limitations of this work. There is no doubt that the research will be continued and measurements will be conducted on a bigger number of young female swimmers. It is advisable that such investigations include female swimmers in the same age group in order to eliminate differences resulting from the body build, therefore, only one group should be assigned according the power and speed dry-land training. The research is going to be expanded by inclusion of the resistance training in the water assigned to the subsequent group of female swimmers in order to reveal which type of training is the most effective. It would be advisable to conduct similar investigations in relation to junior male swimmers. In the future, similar studies may be carried out on swimmers specializing in short-distance swimming $(25 \mathrm{~m}, 50 \mathrm{~m})$.

\section{Conclusions}

On the basis of the investigations conducted and results obtained in this work, it was proven that the introduction of power and speed dry-land training in a group of junior female swimmers aged 15-16 may have a positive impact on the time results obtained while swimming at a distance of $200 \mathrm{~m}$ in the freestyle stroke. It was also shown that the introduced power and speed workout may be of importance while balancing the disproportion between muscle forces of extensors and flexors of the elbow joint. This points to the fact that besides swimming technique and efficiency, the strength parameters play an important role in competitive swimming.

\section{References}

[1] Bassan N.M., SimÕes L.B., Cesar A.S., Caritá R.A.C., De Lima L.C.R., Denadai S.B., GRECo C.C., Reliability of isometric and isokinetic peak torque of elbow flexors and elbow extensors muscles in trained swimmers, Revista Brasilera de Cineantropometria a Desemphenho Humano, 2015, 15 (5), 507-516.

[2] Batalha N., Paixao C., Silva J.A., Costa M., Mullen J., BARBOSA M.T., The effectiveness of dry-land shoulder rotators strength training program in injury prevention in competitive swimmers, J. Hum. Kinet., 2020, 71, 11-20.

[3] Batalha P.N.M., Raimundo M.A., Carus T.P., Fernandes M.S.O., Marinaho A.D., Da Silvan M.R.J.A., Shoulder rotator isokinetic strenght in young swimmers, Brazilian Journal of Kinanthropometry and Human Performance, 2012, 14 (5), 546-553. 
[4] Beek P., Toussaint H., Biomechanics of Competitive Front Crawl Swimming, Sports Medicine, 1992, 13 (1), 8-24.

[5] BŁaszczyk W.J., CIEŚlińsKa-ŚWider J., Plewa M., ZAHORSKa-MarkieWICZ B., MarkiEWICZ A., Effects of excessive body weight on postural control, J. Biomech., 2009, 42, 1295-1300.

[6] Collado-Mateo D., Dominques-Munoz F.J., Batalha N., ParRaca J., CARUS-Tomas P., AdSUAR C.J., Test-Retest Reliability of Isokinetic Arm Strength, Measurements in Competitive Swimmers, J. Hum. Kinet., 2018, 65, 5-11.

[7] Costill D.L., Training adaptations for optimal performance, [in:] K.L. Keskinen, P.V. Komi, A.P. Hollander (Eds.), Biomechanics and Medicine in Swimming VIII, University of Jyvaskyla, Finland, 1999, 381-390.

[8] CZABański B., FiŁon M., Zatoń K., Elements of swimming theory (Elementy teorii plywania, in Polish). AWF Wrocław, Wrocław 2003.

[9] Escalante Y., SaAvedra J.M., Swimming and Aquatic Activities: State of Art., J. Hum. Kinet., 2012, 32, 5-7.

[10] Garcia- Ramos A., Tomazin K., Feriche B., StrojniK V., De La Fuente B., Arguelles-Cinfuegos J., Strumbelu B., STIRIN I., The Relationship Between the Lower-Body Muscular Profile and Swimming Start Performance, J. Hum. Kinet., 2016, 50, 157-165.

[11] Gauchard C.G., Lion A., Bento L., Perrin P.P., Ceyte H., Postural control in high-level kata and kumite karatekas, Movement and Sport Sciences, 2017, 100 (2), 21-26.

[12] Girold S., Calmels P., Maurin D., Milhau N., Chatard J.C., Assisted and resisted sprint training in swimming, J. Strength Cond. Res., 2006, 20, 547-554.

[13] Girold S., Maurin D., Dugue B., Catard J., Millet G., Effects of dry-land vs. resisted and assisted sprint excercises on swimming sprint performances, J. Strength Cond. Res., 2007, 21 (2), 599-605.

[14] Grange J., Gordon R., Success is long term. Long term athlete development related to the journey through swimming, ASA Technical Swimming Committee, 2004.

[15] Gorwa J., Dworak L., MichniK R. et al., Kinematic analysis of modern dance movement , stag jump" within the contex of impact loads, injury to the locomotor system and its prevention, Medical Science Monitor, 2014, 20, 1082-1089.

[16] Gorwa J., MichNIK R.A., NowAKOWSKA-LiPIEC A., JuRKoJĆ J., JOCHYMCZYK-WOŻNIAK K., Is it possible to reduce loads of the locomotor system during the landing phase of dance figures?, Biomechanical analysis of the landing phase in Grand Jeté, Entrelacé and Ballonné, Acta Bioeng. Biomech., 2019, 21 (4), 111-121.
[17] Harbo T., Brincks J., Andersen H., Maximal isokinetic and isometric muscle strength of major muscle groups related to age, body mass, height, and sex in 178 healthy subjects, Eur. J. Appl. Physiol., 2012, 112, 267-275.

[18] Housh T.J., Johnson O.G., Hughes A.R., Housh J.D., Hughes J.R., Fry S.A., KenNEY B.K., CISAR J.C., Isokinetic strength and body composition of high school wrestlers across age, Center for Youth Fitness and Sports Research, 1988, 21 (2), 105-109.

[19] JuRKoJĆ J., Michnik R., CzAPLA K., Mathematical modelling as a tool to assessment of loads in volleyball player's shoulder joint during spike, J. Sports Sci., 2017, 35, 1179-1186.

[20] KARPIŃSKi R., Swimming. Technics Basics, teaching. (Pływanie. Podstawy techniki, nauczanie. in Polish), Academy of Physical Education, Katowice 2011.

[21] Lawsirirat C., Chaisumrej P., Comparison of isokinetic strenghts and Energy systems between short and middle distance swimmers, Journal of Physical Education and Sport, 2017, 17 (3), 960-963.

[22] Lewis W.R., Housh J.T., Traylor A.D., Bergstroom C.H., SCHMIDT J.R., JoHNSON O.G., Housh J.D., Age and isokinetic peak torque at the elbow in young girl swimmers, Isokinet. Excerc. Sci., 2013, 21, 57-61.

[23] RAKOwSKI M., Sport Swimming Training (Sportowy Trening Plywacki, in Polish), Maciej Rakowski, 2010.

[24] Sadowski J., Mastalerz A., Gromisz W., NiźNikowski T., Effectivenes of the Power Dry-Land Training Programmes in Youth Swimmers, J. Hum. Kinet., 2012, 32, 77-86.

[25] SMITH D.J., NorRIS S.R., HoGg J.M., Performance evaluation of swimmers: Scientific tools, Sports Med., 2000, 32, 539-554.

[26] Stewart A.M., Hopkins W.G., Seasonal training and performance of competitive swimmers, J. Sports Sci., 2000, 18, 873-884.

[27] TANAKa H., Swensen T., Impact of resistance training on endurance performance. A new form of cross training?, Sports Med., 1998, 25, 191-200.

[28] Trappe S., Pearson D.R., Effects of weight assisted dry-land strength training on swimming performance, J. Strength Cond. Res., 1994, 8, 209-213.

[29] WiĄżEWICZ A., EIDER J., Assessment of shoulder joint strenght disproportion of master swimmers, Central European Journal of Sport Sciences and Medicine, 2016, 16 (4), 85-90.

[30] Woryna B., Jurkojć J., SKuBACZ H., Biomechanics swimming - aspects of theoretical and experimental of players (Biomechanika plywania - aspekty teoretyczne i badania doświadczalne zawodników, in Polish). Current Problems of Biomechanics, 2014, 8, 169-171. 